\title{
Aplicação do ciclo de ensino e aprendizagem à luz da Pedagogia de Gêneros
}

\section{Application of the Cycle of Teaching and Learning in Light of Genre Pedagogy}

Sandra M. N. de Oliveira*

*Instituto Federal Farroupilha (IFFar), Júlio de Castilhos, Rio Grande do Sul / Brasil sandra.oliveira@iffarroupilha.edu.br

http://orcid.org/0000-0003-1839-8777

RESUMO: $O$ trabalho com leitura e produção escrita é um desafio em turmas de Educação de Jovens e Adultos (EJA), dadas as características particulares dessa modalidade de ensino. Na busca por uma metodologia eficiente, aplicamos, em uma turma de ensino médio, um programa de trabalho com gêneros textuais à luz das orientações da Escola de Sydney (MARTIN; ROSE, 2008; ROSE; MARTIN, 2012), adaptando-o à realidade brasileira. Sendo assim, este artigo objetiva relatar uma experiência realizada em uma turma de ensino médio de EJA e demonstrar que um trabalho de produção de escrita organizado em etapas pode contribuir para o desenvolvimento linguístico de uma classe de alunos que apresentam lacunas na sua formação escolar. Para atingir nosso propósito, sugerimos à turma a produção de relatos autobiográficos em ciclos, para a qual foi realizada a aplicação sequenciada das três etapas que constituem a Pedagogia de Gêneros: Desconstrução, Construção Conjunta e Construção Independente. Os resultados apontam para um crescimento gradual e importante na qualidade das produções textuais dos alunos.

PALAVRAS-CHAVE: Escola de Sydney; pedagogia de gêneros; ciclo de ensino aprendizagem; relatos autobiográficos.

ABSTRACT: Working with reading and writing has been a challenge in Youth and Adult Education (YAE) classes, given the particular characteristics of this teaching modality. In the search for an efficient methodology, we implemented, in a high-school class, a study program with textual genres in light of the Sydney School principles (MARTIN; ROSE, 2008; ROSE; MARTIN, 2012), adapting it to the Brazilian context. Thus, this article aims at reporting an experience undertaken with YAE high school students and demonstrating that staged writing tasks can contribute to the linguistic development of students who have gaps in their school education. For that purpose, we suggested the production of autobiographical reports in cycles, to which the three stages that constitute the Genre Pedagogy - Deconstruction, Joint Construction, 
and Independent Construction - were applied. The results point to gradual and essential improvement in the quality of the students' textual production.

KEYWORDS: Sydney School; genre pedagogy; teaching and learning cycle; autobiographical report.

\section{Introdução}

O conceito de gênero como "um processo social orientado para um fim específico" (ROSE; MARTIN, 2012, p. 1, tradução nossa) surgiu com as pesquisas dos tipos de escrita na escola primária. As estratégias de ensino para guiar os estudantes na escrita de diferentes gêneros ficaram conhecidas como "pedagogia baseada em gêneros", celebradas como "Pedagogia de Gêneros" (OLIVEIRA; CABRAL, 2016). Ela tem como objetivo fazer com que a distribuição de conhecimento na escola seja mais igualitária, tendo como grande diferencial o foco na preparação de todos os alunos para realizarem as tarefas com sucesso (ROSE; MARTIN, 2012).

A inquietação, como professora de língua portuguesa, perante as dificuldades apresentadas na leitura e escrita pelos alunos do Programa Nacional de Integração da Educação Profissional com a Educação Básica na Modalidade Educação de Jovens e Adultos (Proeja) do Instituto Federal Farroupilha (IFFar), do estado do Rio Grande do Sul, levou à realização deste estudo, que é resultado da tese de doutorado ${ }^{1}$ apresentada em dezembro de 2017. A pesquisa está vinculada à linha "Linguagem no Contexto Social" e ao grupo de pesquisa (GRPesq) "Linguagem como prática social”, do Programa de Pós-Graduação em Letras, e atende aos propósitos do projeto do Núcleo de Estudos da Língua Portuguesa (Nelp) do Departamento de Letras Vernáculas. Ela foi aprovada pelo Conselho de Ética em Pesquisa (CEP) com o Certificado de Apresentação para Apreciação Ética (CAAE) no 654 19316.4.0000.5346, Parecer nº 2.009.651. Está inserida na área dos Estudos Linguísticos com uma abordagem sistêmico-funcional, demarcada pelos estudos principalmente de Halliday (1985, 1994), Halliday e Matthiessen (2014), bem como seus seguidores Martin e Rose (2007) e Rose e Martin (2012).

\footnotetext{
${ }^{1}$ Tese de doutorado intitulada "Relatos autobiográficos à luz da pedagogia de gêneros: uma trajetória com intervenção em classe de alunos de Proeja”, orientada pela Profa. Dra. Sara Regina Scotta Cabral da Universidade Federal de Santa Maria (UFSM), a quem eu agradeço pela paciência, dedicação, amizade, troca de experiências e pela orientação segura e competente durante toda a caminhada.
} 
Diante disso, este artigo busca relatar uma experiência realizada por nós em uma turma de Educação de Jovens e Adultos (EJA) e demonstrar que um programa de produção de escrita organizado em etapas pode contribuir para o desenvolvimento linguístico de uma classe de alunos que apresentam lacunas em suas formações escolares. Para realizar este trabalho partimos da hipótese de que, quando temos uma teoria de base e utilizamos materiais e metodologias adequadas, é possível que os alunos demonstrem sensível melhora no processo de escritura de textos. Reiteramos que o trabalho com gênero baseado na escola de Sydney provê, além de metodologia e instrumentos aplicáveis em aulas de leitura e produção textual, orientações ao professor de como proceder nas diversas etapas de construção do texto com os alunos. Em contrapartida, sabíamos que a realidade australiana é bem diferente da brasileira, e que os resultados poderiam ser diferentes. Sabíamos também que as turmas de EJA, em particular, têm legislação e currículo especiais que buscam atender às características dessa modalidade de ensino. Também apostávamos na possibilidade de dar voz àqueles que por muito tempo se sentiam silenciados em meio à sociedade.

Para iniciarmos o trabalho de produção textual, selecionamos o gênero relato autobiográfico que, segundo Martin e Rose (2008), constitui uma série de eventos que se sucedem no tempo. A escolha desse gênero pareceunos adequada, tendo em vista que, além de ser de relativa simplicidade em composição e vocabulário, permitiria aos alunos contarem fatos particulares da sua infância até a idade adulta. A escolha de um gênero de características mais complexas não atenderia ao nosso propósito, que era iniciar as tarefas de leitura e produção para engajar a turma no processo e desenvolver entre eles o gosto pelo trabalho com a linguagem.

Cabe ressaltar estudos relevantes referentes à Escola de Sydney realizados fora do país por Gouveia (2013), da Universidade de Lisboa, e estudos realizados aqui no Brasil, como os de Fuzer (2017), Fuzer et al. (2015, 2016), Muniz da Silva $(2007,2015)$ e Silva (2015). Esses pesquisadores têm aprofundado os estudos baseados na Escola de Sydney e se destacado por adequá-los à realidade brasileira.

Este artigo está composto de quatro seções, além da introdução. $\mathrm{Na}$ primeira, abordamos a Escola de Sydney e o gênero "histórias", que incluem os relatos autobiográficos. Dando continuidade, apresentamos a metodologia com um plano de estudo e os procedimentos de análise das produções dos alunos, bem como a aplicação do ciclo de ensino e aprendizagem proposto 
pela Escola de Sydney em suas três etapas: Desconstrução, Construção Conjunta e Construção Independente (CI). Por fim, as considerações finais.

\section{Escola de Sydney e o gênero das histórias}

O termo "Escola de Sydney" surgiu em 1994 em referência ao trabalho com linguagem e educação feito há pelo menos uma década no Departamento de Linguística da Universidade de Sydney. O projeto se espalhou por escolas e universidades de toda a Austrália e depois tornou-se um movimento internacional, com o objetivo inicial de desenvolver uma pedagogia de escrita que permitisse a qualquer estudante ser bem-sucedido nas atividades exigidas pela escola (OLIVEIRA; CABRAL, 2016). Os responsáveis pela proposta da pedagogia de gênero na abordagem sistêmicofuncional foi o grupo de pesquisadores formado por Joan Rothery, Frances Christie e David Rose e liderados por Jim Martin.

A abordagem da Escola de Sydney, de acordo com Rose (2010, p. 2, tradução nossa), é projetada "explicitamente como intervencionista, seguindo a visão de Halliday de linguística como forma ideologicamente comprometida com a ação social". O conceito de gênero como "um processo social orientado para um fim específico" (ROSE; MARTIN, 2012, p. 1, tradução nossa) surgiu com as pesquisas dos tipos de escrita na escola primária. As estratégias de ensino para guiar os estudantes na escrita de diferentes gêneros ficaram conhecidas como "pedagogia baseada em gêneros", sendo a ação docente nela embasada tida como a "pedagogia de gêneros".

O projeto passou por três grandes fases: a primeira surgiu nos anos 1980, denominada Linguagem e poder social; a segunda, com a descrição dos gêneros que os alunos devem ler e escrever, nos anos 1990, denominada Escrever corretamente; por fim, ocorreu o desenvolvimento de uma metodologia para integrar leitura e escrita com a aprendizagem, na década de 2000, denominada Ler para aprender. O princípio básico do projeto é que o ensino efetivo deve envolver os estudantes com o conhecimento explícito sobre a linguagem (OLIVEIRA, CABRAL, 2016). No interior desses projetos, centenas de produções textuais produzidas pelas crianças em diversas disciplinas escolares foram analisadas e categorizadas com base nos propósitos comunicativos durante sete anos de pesquisa (ROTHERY, 1996).

De acordo com Rose (2015b, p. 6, tradução nossa), "um princípio fundamental da pedagogia de gêneros é que os alunos devem ser preparados 
pelos professores antes de tentarem tarefas de aprendizagem". Martin e Rose (2012) defendem o ensinamento explícito dos gêneros e suas características textuais e linguísticas em que o professor(a) e os objetos de ensino são elementos decisivos junto aos alunos. Para isso, apresenta os ciclos de ensino de gênero: a Desconstrução, a Construção Conjunta e a CI (Figura 1).

FIGURA 1 - Ciclo de ensino e aprendizagem

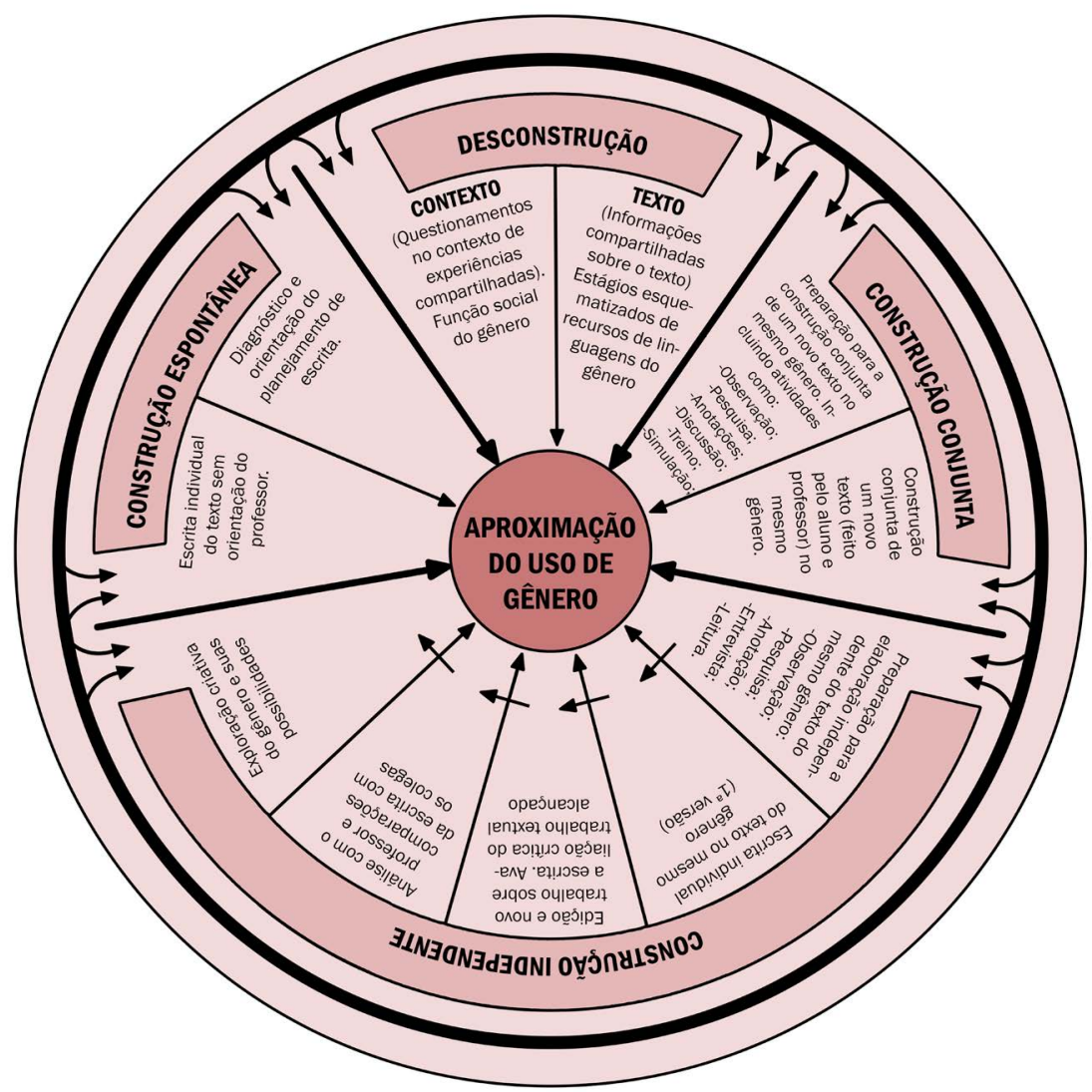

Fonte: adaptado e traduzido de Rose e Martin (2012, p. 64).

$\mathrm{Na}$ negociação do campo, professor e alunos especificam o objetivo da futura produção textual. Na Desconstrução, o professor apresenta detalhadamente modelos do gênero selecionado para produção, visando ao entendimento em relação ao gênero por parte do aluno. Na Construção Conjunta, o objetivo é a escrita do gênero pelo/a professor/a e seus alunos 
em conjunto. Cabe ao professor conduzir o processo de escrita e, na CI, fase final, o objetivo é fazer com que os alunos produzam seus textos, no entanto eles podem recorrer ao professor e seus colegas quando precisarem de orientação. Assim, a pedagogia da escrita do gênero prepara os alunos com a Desconstrução e Construção Conjunta de atividades, antes de tentar a Escrita Independente. O objetivo final do ciclo é que os alunos assumam o controle do gênero, tanto em termos de serem capazes de escrevê-lo quanto de refletirem criticamente sobre os seus papéis (ROSE, 2008). Os autores ressaltam que essas etapas não são fixas e podem ser adaptadas de acordo com as necessidades da turma (MARTIN; ROSE, 2007).

Para Gouveia (2013), conhecer os gêneros escolares trabalhados em diferentes disciplinas curriculares e proporcionar um ensino baseado em gêneros torna os alunos melhores produtores textuais. Segundo o autor, a experiência com os gêneros desenvolve as capacidades e habilidades mentais dos alunos, levando-os a perceberem "que o sucesso escolar em cada disciplina se faz por via do sucesso no domínio dos gêneros escritos e das estruturas léxico-gramaticais próprias da disciplina" (GOUVEIA, 2013, p. 444), e, consequentemente, promovendo o sucesso escolar.

Segundo Muniz da Silva (2015, p. 19), o ciclo de aprendizagem baseado em gêneros "requer a troca de responsabilidade entre professores e estudantes, pois o professor fornece todo o suporte de que os estudantes precisam para se aproximarem e se apropriarem dos gêneros", e os estudantes também assumem responsabilidade por sua própria aprendizagem. Ainda, para a mesma autora, a utilização do ciclo de aprendizagem baseado em gêneros na sala de aula faz com que o professor (a) comprove a "compreensão dos estudantes, (b) engaje-os no processo de aprendizagem, (c) estimule-os a pensar sobre o tema em questão e (d) aplique-os à própria experiência” (MUNIZ DA SILVA, 2015, p. 26). Mendes (2014, p. 41) afirma que "o Ciclo de ensino da pedagogia de gêneros utiliza estratégias que apoiam claramente todos os alunos na elaboração de tarefas complexas de leitura e de escrita em etapas sustentadas". Isso porque em cada etapa o aluno é orientado pelo professor como proceder.

Para Bawarshi e Reiff (2013, p. 53), "o Ciclo ensino-aprendizagem torna visíveis para os estudantes os traços estruturais e linguísticos dos gêneros e mostra como esses traços estão ligados a funções sociais". Usando essa abordagem para a análise do discurso, na primeira fase do projeto foi identificado um conjunto de gêneros que era esperado que os estudantes 
escrevessem na escola primária. Seus propósitos, etapas e principais características linguísticas foram descritos. Conforme Rose e Martin (2012, p. 311, tradução nossa), "os gêneros foram modelados como padrões de configurações linguísticas - os gêneros consistem em significados, e os significados constroem o gênero, localizados para os autores no contexto de cultura".

$\mathrm{Na}$ segunda fase do projeto, Escreva corretamente, a análise de tarefas de aprendizagem foi ampliada para os tipos de conhecimento que se esperavam que os estudantes adquirissem no currículo escolar (ROSE; MARTIN, 2012). Os gêneros que os estudantes leem ou escrevem em cada disciplina do ensino médio foram identificados juntamente com os seus propósitos, etapas e características linguísticas, formando o que foi denominado pelos autores como "Família de Gêneros" (ROSE, 2015b, p. 2). O mapa é apresentado como uma série de escolhas sobre os propósitos do texto que estamos lendo ou escrevendo. De acordo com Rose (2015a), esse mapa é o primeiro passo no planejamento de aulas, e cada parte do mapa é definida como um conjunto de perguntas sobre a finalidade social e a estrutura de cada texto, que leva a identificar o gênero.

O segundo nível da metalinguagem são os nomes das etapas que cada gênero tem de acordo com a proposta social: estórias, histórias, explicações, procedimentos, relatórios, argumentos e respostas ao texto. ${ }^{2}$ A gama de gêneros descritos na pesquisa da Escola de Sydney é grande e diversificada, mas ainda é apenas uma fração do repertório de gêneros disponíveis para membros de uma cultura (ROSE, 2015a, p. 1).

\subsection{Os gêneros das histórias}

A partir dos anos finais do ensino fundamental, os textos mais estudados são os gêneros informativos, argumentativos e avaliativos. Nos informativos, aparecem as histórias que são uma família de "gêneros orientados para eventos que evoluíram para construir e manter a ordem social em uma escala mais ampla, de povos e suas instituições" (MARTIN; ROSE, 2008, p. 97, tradução nossa). Os autores consideram que essa família tenha evoluído em contextos institucionais que costumam registrar, explicar e debater o passado. As histórias caracterizam-se pelo modo como o tempo é manipulado para ordenar eventos passados, como a causa é

\footnotetext{
${ }^{2}$ A respeito das famílias de gêneros, cf. Rose e Martin (2012) e Rose (2015a).
} 
utilizada para explicá-los e como a avaliação é utilizada para julgar uma ou outra interpretação (MARTIN; ROSE, 2008). De uma perspectiva teórica, também se muda a estratégia para relacionar os gêneros uns aos outros, da tipologia, como uma hierarquia de agrupamentos, para a topologia, como regiões de convergência entre os gêneros. Entendemos que isso possibilita propor um caminho de aprendizagem para os estudantes nessa família de gêneros, particularmente orientado para os currículos do ensino médio.

Os gêneros da família das histórias incluem os relatos autobiográficos, nos quais o escritor conta os eventos principais em sua vida; os relatos biográficos, que estabelecem as fases na vida de uma pessoa; os relatos históricos, que estabelecem as fases em um período da história, e as explicações históricas, que explicam acontecimentos históricos. A autobiografia é um gênero que favorece o estilo individual do autor. O contato com exemplares de texto do gênero contribui para que o aluno identifique suas características peculiares e tenha um direcionamento para a escrita, pois, como afirma Bakhtin (2003, p. 285), "quanto melhor dominamos os gêneros tanto mais livremente os empregamos, tanto mais plena e nitidamente descobrimos neles a nossa individualidade".

Para Rose e Martin (2012), o gênero relato autobiográfico tem o propósito de recontar os eventos da própria vida, seguindo as etapas de a) orientação e b) registro de etapas. A etapa de orientação traz informações sobre quem, quando e onde, e o registro de etapas são os passos mais previsíveis do gênero com fatos importantes na vida de cada pessoa, contados em ordem cronológica. Qualquer texto terá mais de um objetivo, mas é o seu propósito central que determina as etapas pelas quais o texto passará para atingi-lo. Cada etapa de um gênero também inclui uma ou mais fases, que podem ser variáveis. Elas organizam a estrutura global de cada texto, mas as fases determinam como elas se desenvolvem dentro dessa estrutura global. Cada fase tem um objetivo principal, já que cada parágrafo em um texto geralmente tem uma ideia principal (ROSE, 2015b).

Para Rose (2010, p. 6, tradução nossa),

embora a implantação de fases em histórias seja altamente variável, os relatos biográficos são mais previsíveis. Eles também começam com uma Orientação, que tipicamente traça o nascimento e o início da vida da pessoa, e talvez as razões para sua fama, e siga com as etapas de sua vida, ou etapas de vida. Cada fase da vida da pessoa é uma fase do texto, e é tipicamente sinalizada por um tempo ou lugar, como ponto de partida de uma frase. 
Rose (2006, p. 2) também enfatiza que a relação entre gêneros, etapas, fases e mensagens não é simplesmente de composição, mas também de realização. Um gênero é realizado por suas etapas, as etapas por suas fases e as fases, por suas mensagens.

\section{Metodologia}

Este artigo é resultado de um trabalho de pesquisa-ação a partir das orientações dos estudos de gêneros textuais da Escola de Sydney, com base na teoria sistêmico-funcional, aplicado em uma turma de $19^{3}$ alunos do primeiro ano de ensino médio de EJA, do Curso Técnico em Comércio do IFFar do Estado do Rio Grande do Sul, nos anos de 2016 e 2017. ${ }^{4}$ Os alunos tinham, na época, diferentes idades, predominando a adulta (de 20 a 50 anos), que haviam deixado de estudar há tempo, tinham filhos, trabalhavam durante todo o dia, tinham baixa renda e apresentavam dificuldades de expressão tanto na escrita como na oralidade. Essas pessoas haviam retornado à escola na expectativa de enfrentar a exclusão social e de obter um trabalho digno, buscando aumentar a renda para melhorar suas vidas.

Inicialmente aplicamos um trabalho de produção textual, a que chamamos de Construção Espontânea (CE), sem menção, por parte da professora, da constituição do gênero e de suas marcas textuais, discursivas e composicionais. Dessa fase, obtivemos uma avaliação diagnóstica importante. Essa etapa não está prevista nas orientações da Escola de Sydney, mas a julgamos necessária para organizarmos nossas ações posteriores. De posse dessa avaliação, elaboramos um plano de trabalho para a produção de autobiografias, o qual consistiu nas seguintes fases:

a) realização de um diagnóstico acerca das habilidades dos alunos no processo de escrita bem como das fragilidades linguístico-discursivas e estruturais no texto produzido;

b) elaboração, com base no diagnóstico obtido, de um plano de trabalho que culminasse com a produção da autobiografia de cada estudante;

c) realização de atividades de preparação para iniciar o processo de escrita - conhecendo o campo e as relações;

\footnotetext{
${ }^{3} \mathrm{O}$ número de alunos oscilou durante a pesquisa. Entretanto, 14 deles iniciaram e terminaram os ciclos.

${ }^{4}$ No decorrer do curso houve cancelamentos de matrícula por parte de alguns alunos.
} 
d) trabalho de Desconstrução de exemplares de autobiografias;

e) trabalho de Construção Conjunta de um possível exemplar de uma autobiografia;

f) realização da etapa de CI de uma autobiografia;

g) avaliação das fragilidades e pontos fortes demonstrados nos textos produzidos;

h) retomada do processo de escritura da autobiografia; e

i) avaliação da última versão comparada com a primeira.

Todos esses passos tiveram duas motivações: o contato com um gênero ainda não trabalhado e talvez até desconhecido por parte da turma e a grande dificuldade constatada na produção textual realizada espontaneamente.

A seguir, na Desconstrução, realizamos atividades com o intuito de levar os alunos a olharem para si mesmos e escreverem sobre suas vidas. Uma série de atividades foi desenvolvida com trabalhos orais e escritos bem como o estudo de outras autobiografias para observar a estrutura, suas características linguísticas e realizar uma leitura crítica sobre o propósito do gênero. Utilizamos, nesta fase, autobiografias de escritores conhecidos, objetos pessoais e significativos dos alunos, álbuns de fotografias da família e também realizamos trabalho transdisciplinar com as disciplinas de Biologia e Filosofia. Por ocasião da Construção Conjunta, os alunos, juntamente com a professora, produziram uma autobiografia ficcional, ocasião em que foram colocadas em prática as características linguísticas e a estrutura composicional do gênero escolhido. Por fim, na terceira fase, chamada de CI, os alunos produziram sua autobiografia individualmente.

Após a análise dos textos produzidos, observamos ainda algumas dificuldades apresentadas pelos alunos em sala de aula, embora eles tenham demonstrado considerável amadurecimento na escrita. Passamos então a nos dedicar a sanar os problemas restantes, com a finalidade de produzir a última versão. A partir dessa reelaboração, cotejamos os resultados obtidos com o crescimento individual dos alunos.

Para acompanhamento e avaliação de nosso trabalho, empregamos como suporte, além dos textos elaborados pelos alunos, fichas e quadros que elaboramos com os critérios de avaliação do desempenho dos estudantes quanto à configuração do contexto de produção dos textos, discurso, gramática e apresentação gráfica (Quadro 1) com base em Rose e Martin 
(2012). Contemplamos quatro níveis de desempenho na produção textual: Muito Bom, Bom, Regular e Insuficiente, o que explicitamos também no Quadro 1.

QUADRO 1 - Critérios de avaliação da escrita

\begin{tabular}{|c|c|c|}
\hline \multirow[t]{2}{*}{ 1. CONTEXTO } & Avaliação & $\begin{array}{lc}\mathbf{I}=\text { insuficiente } & \mathbf{R}=\text { regular } \\
\mathbf{B}=\text { bom } & \mathrm{MB}=\text { muito bom }\end{array}$ \\
\hline & \multicolumn{2}{|c|}{ Adequação ao gênero e configuração contextual } \\
\hline Propósito & $\mathrm{MB} / \mathrm{B} / \mathrm{R} / \mathrm{I}$ & $\begin{array}{l}\text { Quão apropriado e bem desenvolvido é o gênero com a finalidade } \\
\text { de escrita? }\end{array}$ \\
\hline Etapas & $\mathrm{MB} / \mathrm{B} / \mathrm{R} / \mathrm{I}$ & $\begin{array}{l}\text { O texto passa por estágios apropriados? Quão bem cada etapa é } \\
\text { desenvolvida? }\end{array}$ \\
\hline Fases & $\mathrm{MB} / \mathrm{B} / \mathrm{R} / \mathrm{I}$ & Quão bem organizada é a sequência de fases no texto? \\
\hline \multirow{4}{*}{$\begin{array}{l}\text { Campo } \\
\text { O que está acontecendo? } \\
\text { O gênero produzido é } \\
\text { relato autobiográfico? }\end{array}$} & MB & $\begin{array}{l}\text { O texto é um relato autobiográfico com as etapas do gênero - } \\
\text { orientação e registro de etapas? }\end{array}$ \\
\hline & $\mathrm{B}$ & $\begin{array}{l}\text { O relato apresenta poucas informações com, no mínimo, duas } \\
\text { etapas da vida? }\end{array}$ \\
\hline & $\mathrm{R}$ & O relato apresenta uma etapa da vida? \\
\hline & I & O texto produzido não é um relato. \\
\hline \multirow{4}{*}{$\begin{array}{l}\text { Relações } \\
\text { Há presença do autor } \\
\text { e/ou receptor no texto } \\
\left(1^{\mathrm{a}}, 2^{\mathrm{a}} \text { e } 3^{\mathrm{a}} \text { pessoas, }\right. \\
\text { prevalecendo o eu? }\end{array}$} & MB & $\begin{array}{l}\text { O texto foi produzido com o uso do "eu, ela(s), ele(s) dentro do } \\
\text { texto", com predominância do "eu"? }\end{array}$ \\
\hline & $\mathrm{B}$ & $\begin{array}{l}\text { O texto foi produzido com o uso do "eu, tu, nós" com } \\
\text { predominância do "eu"? }\end{array}$ \\
\hline & $\mathrm{R}$ & $\begin{array}{l}\text { O texto foi produzido com o uso do "eu, tu, eles, nós e vocês" sem } \\
\text { predominância do "eu"? }\end{array}$ \\
\hline & I & O texto foi produzido sem o uso do "eu"? \\
\hline \multirow{2}{*}{$\begin{array}{l}\text { Modo } \\
\text { Linguagem usada? } \\
\text { É falada demais? }\end{array}$} & MB & A linguagem escrita é adequada ao estágio escolar dos alunos? \\
\hline & I & Há predominância da oralidade. \\
\hline 2. DISCURSO & \multicolumn{2}{|c|}{ Os critérios do discurso estão marcados no texto para dar uma medida precisa } \\
\hline Ideação $^{5}$ & $\mathbf{M B} / \mathbf{B} / \mathbf{R} / \mathbf{I}$ & $\begin{array}{l}\text { Quais são os recursos lexicais do escritor? Quão bem o léxico é } \\
\text { utilizado para construir o campo? }\end{array}$ \\
\hline Avaliação & $\mathbf{M B} / \mathbf{B} / \mathbf{R} / \mathbf{I}$ & $\begin{array}{l}\text { Quais são os recursos de avaliação do escritor? Quão bem a } \\
\text { avaliatividade é usada para engajar, persuadir e avaliar? }\end{array}$ \\
\hline Conjunção & $\mathbf{M B} / \mathbf{B} / \mathbf{R} / \mathbf{I}$ & Há uma relação lógica clara entre todas as sentenças? \\
\hline Identificação & $\mathbf{M B} / \mathbf{B} / \mathbf{R} / \mathbf{I}$ & Está claro quem ou o que é referido em cada sentença? \\
\hline
\end{tabular}

${ }^{5}$ Ideação, avaliatividade, conjunção e identificação são os nomes de quatro sistemas discursivos em Linguística Sistêmico-Funcional (MARTIN, ROSE, 2007). Segundo esses autores, a ideação refere-se à construção da experiência no discurso, incluindo pessoas, coisas, lugares e qualidades associadas a elas; a avaliatividade diz respeito ao modo como avaliamos o mundo; a conjunção constrói os significados que interconectam os processos realizados no texto; e a identificação abrange os recursos de coesão gramatical e semântica empregados no desenvolvimento de um texto. 


\begin{tabular}{|l|l|l|}
\hline $\begin{array}{l}\text { 3. GRAMÁTICA E } \\
\text { CARACTERÍSTI } \\
\text { CAS GRÁFICAS }\end{array}$ & \multicolumn{2}{|l|}{ Características gramaticais são avaliadas no geral, em vez de uma a uma } \\
\hline Gramática & $\mathrm{MB} / \mathrm{B} / \mathbf{R} / \mathbf{I}$ & $\begin{array}{l}\text { Existe uma variedade adequada de estruturas de sentenças e grupos } \\
\text { de palavras para a etapa escolar? }\end{array}$ \\
\hline Ortografia & $\mathrm{MB} / \mathrm{B} / \mathrm{R} / \mathrm{I}$ & $\begin{array}{l}\text { Quão precisamente escritas são as palavras centrais e as palavras } \\
\text { não essenciais? }\end{array}$ \\
\hline Pontuação & $\mathrm{MB} / \mathrm{B} / \mathrm{R} / \mathrm{I}$ & Quão apropriada e precisamente a pontuação é utilizada? \\
\hline Apresentação & $\mathrm{MB} / \mathrm{B} / \mathrm{R} / \mathrm{I}$ & $\begin{array}{l}\text { São utilizados parágrafos? Quão legível é a escrita? O layout é claro? } \\
\text { As ilustrações/diagramas são utilizados apropriadamente? }\end{array}$ \\
\hline
\end{tabular}

Fonte: adaptado de Rose e Martin (2012, p. 323-324).

Com base no Quadro 1, elaboramos uma ficha de avaliação (Quadro 2), em que atribuímos um conceito para cada item e para cada aluno participante da pesquisa.

QUADRO 2 - Ficha de avaliação dos relatos individuais

\begin{tabular}{|c|c|c|c|c|c|c|c|c|c|c|c|c|c|c|}
\hline \multirow[b]{3}{*}{ TEXTOS } & \multicolumn{6}{|c|}{ CONTEXTO } & \multicolumn{4}{|c|}{ DISCURSO } & \multicolumn{4}{|c|}{ GRAMÁTICA } \\
\hline & I & $\mathrm{R}$ & B & M & & & I & B & MB & & I $\mathrm{F}$ & B & MB & \\
\hline & 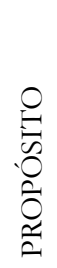 & 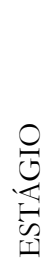 & 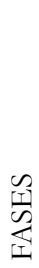 & 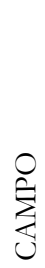 & 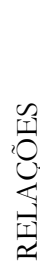 & $\stackrel{0}{\stackrel{0}{2}}$ & 㥕 & 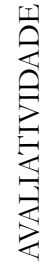 & 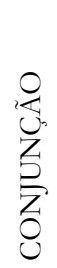 & 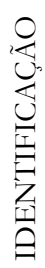 & 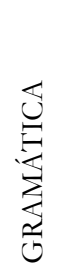 & 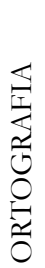 & 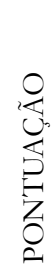 & 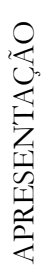 \\
\hline Aluno A & & & & & & & & & & & & & & \\
\hline Aluno B & & & & & & & & & & & & & & \\
\hline$\ldots$ & & & & & & & & & & & & & & \\
\hline
\end{tabular}

Fonte: elaborado pelo autor.

$\mathrm{Na}$ próxima seção, apresentamos a aplicação do ciclo de ensino e aprendizagem: Desconstrução, Construção Conjunta e CI, os resultados obtidos e a sua discussão. 


\section{Aplicação do Ciclo de ensino e aprendizagem}

Passamos agora ao detalhamento das atividades realizadas em sala de aula com nossos alunos, para as quais procedemos com uma metodologia de aplicação, acompanhamento, avaliação, discussão e reformulação do processo de escrita de autobiografias em uma turma de ensino médio de EJA. Caracterizamos nosso trabalho como pesquisa-ação, para a qual aplicamos o ciclo de aprendizagem preconizado pela escola australiana, mas adaptado ao contexto de produção dos alunos. Paralelamente à descrição, realizamos a interpretação dos resultados obtidos em cada uma das fases de aplicação do ciclo. Nossa postura interpretativista é proveniente do cotejo entre os pressupostos de Martin e Rose (2008) e Rose e Martin (2012) e as produções da turma em que a pesquisa foi realizada.

\subsection{Primeira versão dos relatos autobiográficos e análise diagnóstica}

Após a apresentação detalhada de nosso plano de trabalho e consequente adesão da turma à nossa proposta de aplicação do ciclo de aprendizagem, propusemos aos alunos a produção espontânea de um relato autobiográfico sem nenhuma informação sobre o gênero. Eles se questionaram sobre o que era uma autobiografia, ao que alguns responderam "é falar da gente mesmo". Após os comentários, iniciaram o processo de escrita. É importante ressaltar que, para esse primeiro texto, não demos orientação sobre estrutura composicional ou marcas linguísticas do gênero escolhido aos estudantes. Esse procedimento, para nós, foi de muita valia, pois pretendíamos observar a realidade da turma em termos de escrita e também mapear os pontos fortes e as fragilidades dos seus textos. A essa primeira tarefa denominamos CE.

Uma vez recolhidos e analisados pela professora, os textos foram devolvidos aos alunos e comentados, primeiro individualmente, por meio de conversa com cada um para mostrar as inconsistências apresentadas, e posteriormente em grupo. Após, passamos a trabalhar questões em sala de aula, naturalmente, sem apontar nomes de alunos que incorreram na inadequação.

As maiores dificuldades apresentadas referiram-se ao contexto, que diz respeito aos itens propósito, etapas, fases e campo. Predominaram os conceitos regular e insuficiente, com apenas um conceito muito bom e sete bons. Muitos estudantes não produziram um relato, mas sim fizeram uma 
descrição de si ou reflexões sobre a vida no geral e, também, expuseram seus desejos em relação ao futuro.

Quanto ao discurso, que abrange ideação, avaliatividade, conjunção e identificação, os alunos mostraram mais desenvoltura na identificação, referindo quem ou o quê em cada sentença de forma clara. No item conjunção, em alguns textos, constatamos dificuldades no estabelecimento de relações lógicas adequadas entre as sentenças e os parágrafos, predominando o conceito regular e bom. Em avaliatividade, ou não foram usados itens avaliativos ou o foram em excesso, o que não é uma característica do gênero em estudo. $\mathrm{Na}$ ideação prevaleceu o conceito regular. No que concerne à gramática, que compreende itens como ortografia, pontuação e apresentação, alguns alunos mostraram várias dificuldades, principalmente de pontuação. Quanto à apresentação, a maioria obteve o conceito bom.

Após a realização e análise da $\mathrm{CE}$ aula, passamos à aplicação do ciclo de ensino e aprendizagem proposto pela Pedagogia de Gêneros da Escola de Sydney que, como já vimos, apresenta três etapas: Desconstrução, Construção Conjunta e CI. Os três estágios da pedagogia envolvem tanto o campo de construção (para que os alunos estejam familiarizados com o conteúdo dos textos que estão lendo e escrevendo) quanto da contextualização (para que os alunos compreendam o propósito social do gênero). O objetivo final do ciclo é que eles aprendam a produzir o gênero proposto e reflitam criticamente sobre essa prática discursiva e sobre a função social desse gênero.

\subsection{Desconstrução}

Após a combinação, com os alunos, acerca do gênero a ser trabalhado - relato autobiográfico ou autobiografia -, começamos a etapa da Desconstrução. Para melhor visualização do caminho por nós percorrido, apresentamos, na Figura 2, primeira etapa do Ciclo de Ensino e Aprendizagem proposto pela escola de Sydney - a Desconstrução. 
FIGURA 2 - Etapa da Desconstrução

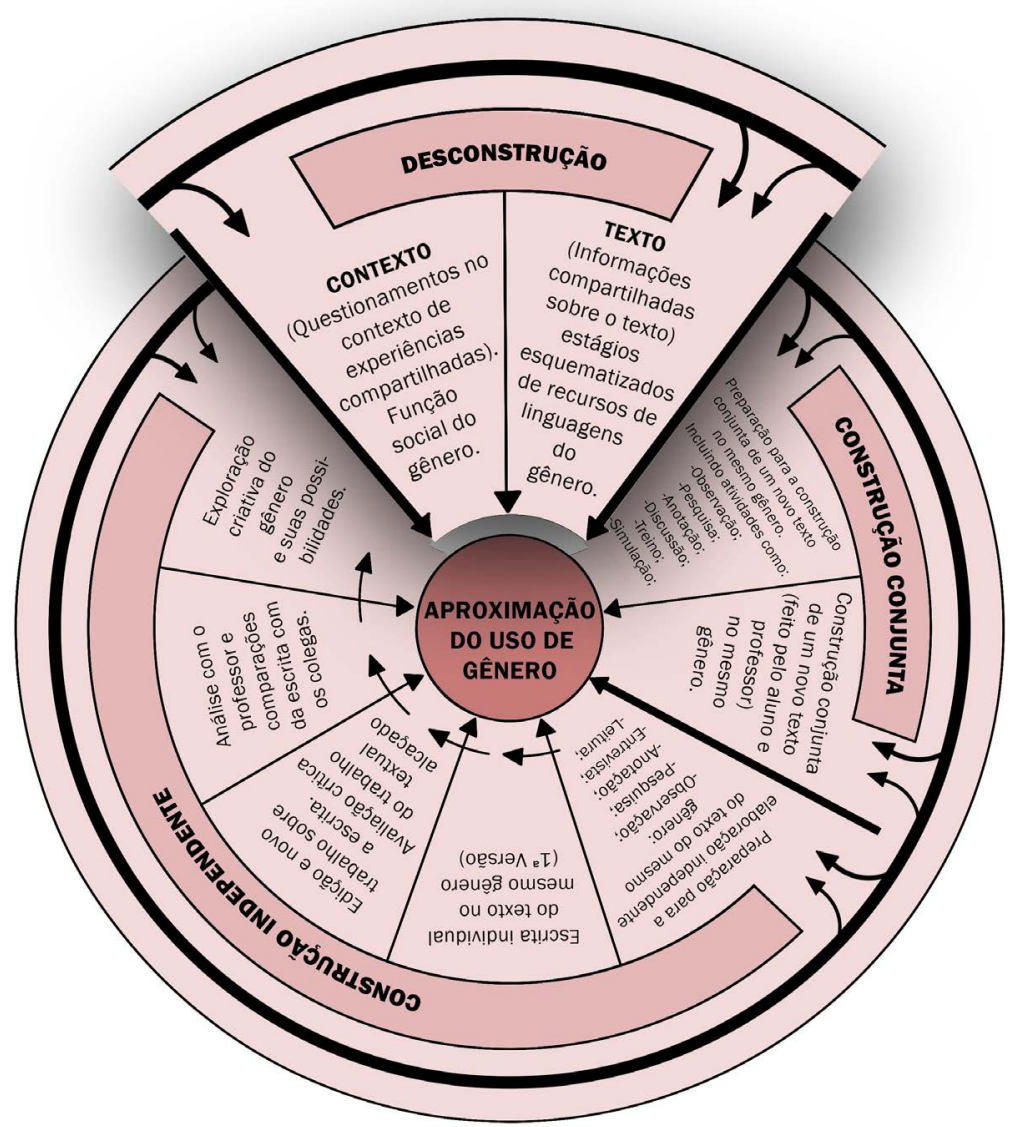

Fonte: adaptado e traduzido de Rose e Martin (2012, p. 64).

Para iniciar os trabalhos, pensamos em realizar algumas atividades que propiciassem uma reflexão sobre a vida antes de trabalhar a desconstrução do gênero propriamente dito, para que cada um fosse se sentindo à vontade para falar de si mesmo. Percebemos que, inicialmente, os alunos pareciam não se sentir muito confortáveis para falar sobre si mesmos, como se suas histórias não fossem relevantes e diziam, ainda, que não sabiam por onde começar. Como escreveu o aluno cujo pseudônimo é Capitão Rodrigo, em seu primeiro relato, "falar sobre problemas sociais, sobre realidade de um fato ou até mesmo sobre outro alguém é um pouco fácil se comparado com a difícil tarefa de falar de alguém único, mas guardião de muitos, ou 
seja, nós mesmos". Diante disso, propusemos uma sequência de atividades com o objetivo de reunir subsídios para a escrita do relato autobiográfico final: discussão sobre os gêneros musicais; audição de músicas; leitura de biografias; trabalho no laboratório de informática e elaboração da biografia de Patch Adams; trabalho transdisciplinar com professores de Filosofia (acerca do existencialismo) e Biologia (árvore genealógica); análise e exposição de poemas com o tema "Autorretratos"; trabalho com álbuns de família; dentre outros. Finalmente, procedemos à desconstrução da autobiografia de Monteiro Lobato.

Concluída essa etapa, passamos à Construção Conjunta.

\subsection{Construção Conjunta}

Nesta etapa, o objetivo é a produção compartilhada de um relato/ biografia, ou seja, alunos e professora interagindo com um objetivo comum. É um momento que propicia troca de experiências, interação por parte do grupo e troca de opiniões, sendo que o papel do professor é essencial para a condução do processo, porque ele(a) passa a atuar como âncora para conduzir as discussões e organizar as ideias. A Figura 3 ilustra esta etapa. 
FIGURA 3 - Etapa da Construção Conjunta

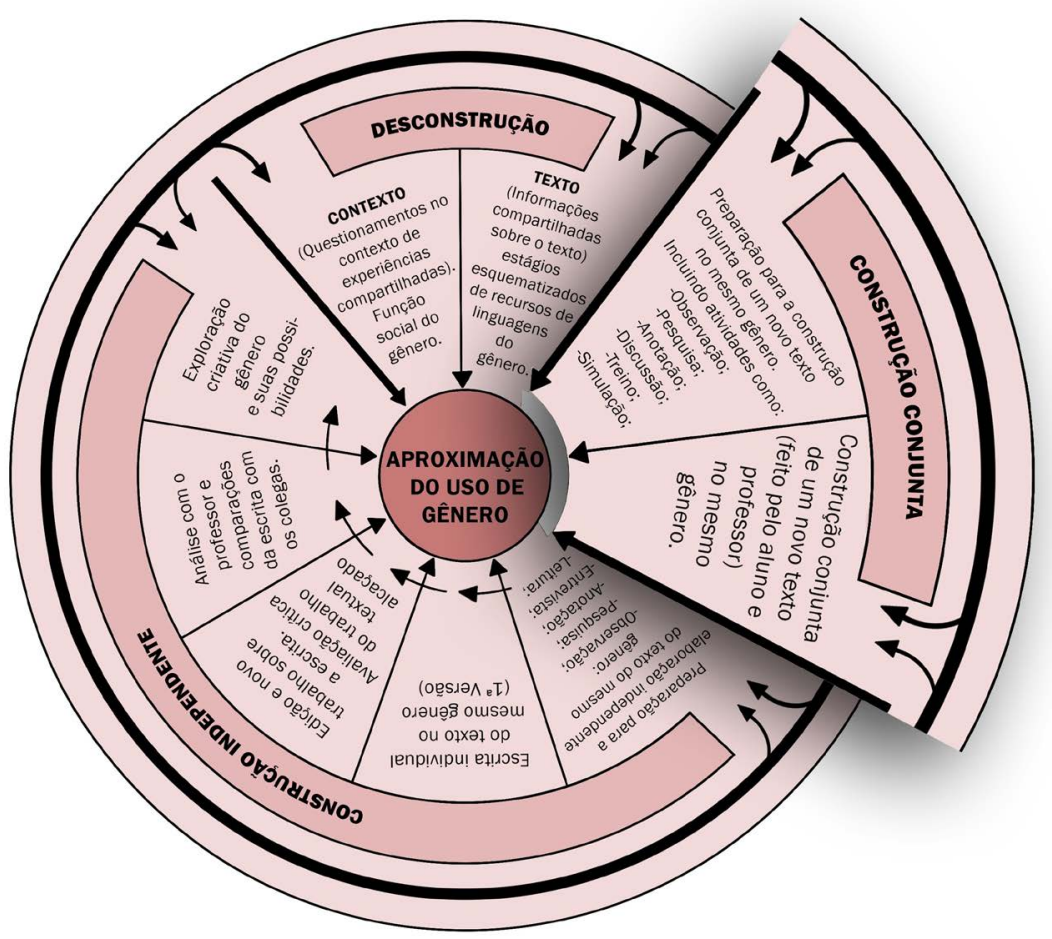

Fonte: adaptado e traduzido de Rose e Martin (2012, p. 64).

Durante a execução da Construção Conjunta, professor e alunos produziram um relato autobiográfico escrito similar ao discutido anteriormente. Utilizando a técnica do brainstorming, ${ }^{6}$ o grupo foi lançando diferentes ideias no quadro verde e, no datashow, fomos organizando compartilhadamente o texto. Após o consenso do que seria escrito, as ideias eram colocadas em slides e, assim, o texto foi sendo construído. O uso do datashow permitiu que a escrita fosse acompanhada e copiada por toda a turma.

Esta etapa é interativa e tida como essencial pelos teóricos do ciclo de ensino e aprendizagem, possibilitando que as dificuldades dos aprendizes venham à tona. Nesta atividade, mediada tanto pelo professor como pelos

\footnotetext{
${ }^{6} \mathrm{O}$ brainstorming (literalmente "tempestade cerebral" em inglês) ou tempestade de ideias é uma atividade desenvolvida para explorar a potencialidade criativa de um indivíduo ou de um grupo.
} 
alunos, é viável também o compartilhamento de saberes, dúvidas e soluções de problemas. Julgamos que a atividade interessante e gratificante, pois houve a participação intensa dos alunos.

A avaliação foi baseada nos critérios propostos para a primeira e última versões, uma vez que entendemos que simultaneamente, no processo de construção do texto, as situações foram pensadas e avaliadas por todos os participantes da Construção Conjunta.

\subsection{Construção Independente}

Depois da Construção Conjunta, partimos para a CI, etapa em que os alunos devem estar aptos a produzir os seus textos e refletir criticamente sobre o seu propósito. O destaque na Figura 4 representa a etapa em tela do nosso trabalho com o ciclo.

FIGURA 4 - Etapa da Construção Independente

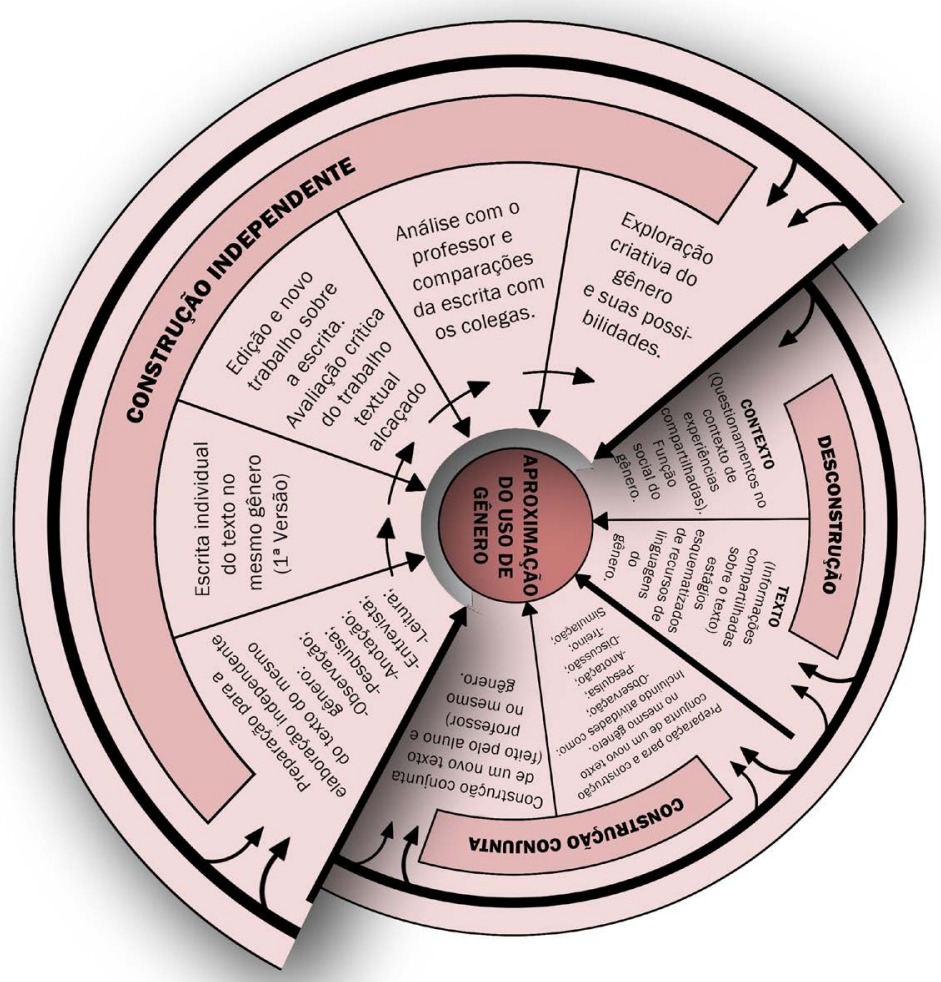

Fonte: adaptado e traduzido de Rose e Martin (2012, p. 64). 
Por ocasião da CI, os alunos foram convidados a escreverem seus relatos que posteriormente foram avaliados pela professora e devolvido aos alunos com algumas sugestões, buscando ajustar o texto ao contexto de produção, bem como a adequação de aspectos gramaticais e discursivos.

\subsection{Análise comparativa da primeira e última versão produzidas pela turma de Proeja}

Nesta seção, apresentamos um comparativo entre os textos produzidos na CE e na CI, de modo a expor o desenvolvimento alcançado pela turma em relação à produção de suas autobiografias. ${ }^{7}$

\subsubsection{Contexto}

O critério contexto (Quadro 1) abrange as variáveis propósito, fases e etapas, além da configuração contextual (HASAN, 1989): campo (o que está acontecendo), relações (quem está participando) e modo (como a linguagem é empregada).

$\mathrm{Na} \mathrm{CE}$, a maioria dos alunos não atendeu completamente a tais requisitos. A principal fragilidade encontrada, na primeira versão, diz respeito à estrutura composicional do gênero relato autobiográfico (orientação e registro das etapas). A maioria dos textos apresentou orientação, mas as etapas restantes não foram definidas. Enquanto alguns demarcaram os períodos de vida, outros não o fizeram e produziram reflexões sobre episódios ou questões morais e éticas, bem como a exposição de desejos, sonhos e medos. Em consequência disso, a estrutura composicional ficou comprometida. As dificuldades na variável campo mostraram-se como descrições particulares e reflexões momentâneas sobre uma fase da vida dos estudantes ou características individuais (Exemplo 1). ${ }^{8}$

\footnotetext{
${ }^{7}$ Não apresentamos aqui exemplos das fases intermediárias, tendo em vista a limitação de espaço para este artigo.

${ }^{8}$ Os exemplos retirados dos textos dos alunos estão apresentados sem correção de nossa parte.
} 


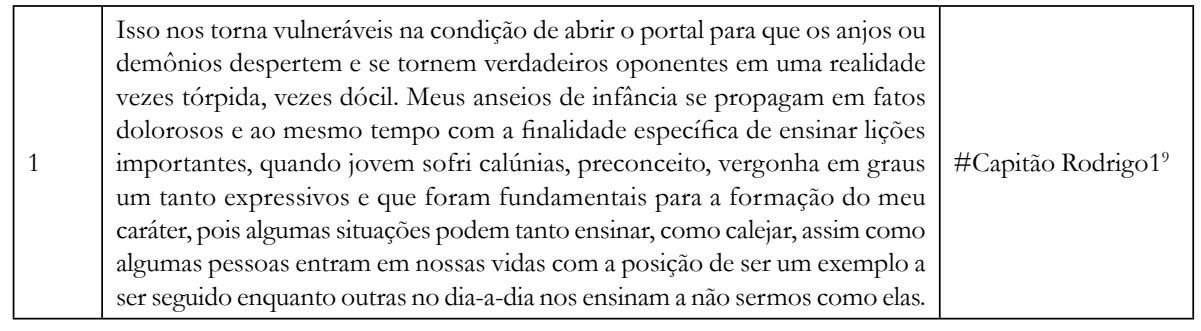

\section{Já na CI, Capitão Rodrigo assim escreveu:}

\begin{tabular}{|l|l|l|}
\hline 2 & $\begin{array}{l}\text { Minha infância foi de certa forma feliz, numa geração em que a tecnologia } \\
\text { não reinava, eu e meus tios brincávamos na rua até tarde, jogando bola, o } \\
\text { popular "Taca". Lembro-me de correr no terreiro de casa atrás da galinhas e } \\
\text { dos cachorros que meu avô a vida inteira criou. }\end{array}$ & \#Capitão Rodrigo2 \\
\hline
\end{tabular}

No Exemplo 2, \#Capitão Rodrigo mostra seu entendimento em relação ao propósito e à estrutura composicional do gênero proposto, pois reconta eventos de sua vida cumprindo uma das etapas exigidas no registro de etapas, conforme sugerem Rose e Martin (2012). O modo como os alunos exploraram o campo foi satisfatório aos propósitos do gênero (Exemplo 3).

\footnotetext{
3 Meu nome é... nasci em..., Tudo começou quando..., Quando eu fiz quatorze anos..., Com dezesseis anos..., ... três anos depois ..., ... agora ... trinta anos após ...
}

\#Negra1

No critério relações, em que a presença do autor se faz com a prevalência da primeira pessoa, avaliamos que os alunos foram bem, embora sem nenhuma orientação sobre o gênero. Salientamos que observamos também a presença do receptor entre os participantes do texto e fora do texto. Nesse caso, os textos constituem, predominantemente, uma declaração para os colegas e para a professora, conforme demonstra o Exemplo 4.

\footnotetext{
${ }^{9}$ Durante o trabalho, solicitamos aos alunos que atribuíssem a si codinomes. $\mathrm{Na}$ indicação dos autores dos excertos utilizados como exemplo neste artigo, acrescentamos o número 1 para indicar a etapa da CE e o número 2 para indicar a fase da CI.
} 


\begin{tabular}{|l|l|l|}
\hline 4 & $\begin{array}{l}{[\ldots] \text { espero que deus me ajude e me ilumine meus caminhos e os seus para quem }} \\
\text { estiver lendo minha história e é isso vim parar aqui no IFF Júlio de Castilhos } \\
\text { fazendo minha Autobiografia espero que tenha gostado um forte abraço fique } \\
\text { com deus. }\end{array}$ & \#Sonhador 2 \\
\hline
\end{tabular}

$\mathrm{Na} \mathrm{CI}$, \#Moreninha manteve marcada a presença da primeira pessoa para contar a sua história de vida (Exemplo 5), o que deixa claro o seu entendimento quanto à escolha adequada do pronome na produção do gênero autobiografia.

\begin{tabular}{|l|l|l|}
\hline 5 & $\begin{array}{l}\text { Já na minha juventude aos } 14 \text { anos parei de estudar e comecei a namorar e depois } \\
\text { de dois meses casei com o meu primeiro namorado e no fim do ano descobri } \\
\text { que estava grávida e de aniversário ganhei minha casa e fui morar com meu } \\
\text { namorado e meu filho. }\end{array}$ & \#Moreninha2 \\
\hline
\end{tabular}

O modo, por sua vez, apresentou-se previsível, já que havíamos entregado aos alunos uma folha de papel para a escritura dos textos. Nos primeiros textos, observamos marcas do uso da oralidade, como no Exemplo 6.

$6 \quad$ Bueno, ${ }^{10}$ agora vou falar um pouco de mim $\quad$ \#Potro Moro1

A pouca familiarização com a escrita e a leitura, decorrente do afastamento do ambiente escolar durante muitos anos, pode ser um fator determinante para a inserção da oralidade na primeira versão. Esse foi um dos motivos que nos levou a aplicar o Ciclo de Ensino e Aprendizagem nessa turma, tendo em vista acompanhar o desenvolvimento da escrita em um grupo que apresentava muitas fragilidades.

$\mathrm{Na}$ última versão, os alunos alcançaram conceito Muito Bom em todos os itens no critério contexto.

\footnotetext{
${ }^{10}$ Bueno é uma expressão muito utilizada no Rio Grande do Sul e significa: Adj. bom, bondoso. Adv. Está bem; muito bem; perfeitamente.
} 


\subsubsection{Discurso}

O critério discurso diz respeito aos sistemas discursivos ideação, conjunção, avaliatividade e identificação. $\mathrm{Na}$ primeira versão, percebemos que, quanto ao sistema de ideação, processos, participantes e circunstâncias estão presentes, mas de maneira aleatória. Observamos que não há menção a muitos familiares e amigos em favor da presença do "eu". Os processos mais empregados são os relacionais e as circunstâncias não demarcam com precisão a sequência temporal das etapas da vida até então (Exemplo 7).

\begin{tabular}{|l|l|l|}
\hline 7 & $\begin{array}{l}\text { Eu Moreninha tenho } 20 \text { anos sou casada e tenho } 2 \text { filhos lindos e me considero } \\
\text { muito feliz pois tenho quase tudo que eu quero o que é bom não ter tudo, por que } \\
\text { se eu já tivesse tudo não teria o incentivo a ajuda e o apoio que minha família me dá } \\
\text { hoje para seguir em frente com os estudos que considero um dos primeiros passos } \\
\text { para ser uma pessoa melhor e ate mesmo para poder ajudar alguem que precise da } \\
\text { minha ajuda ou referencia no caso meus filhos. }\end{array}$ & \# Moreninha1 \\
\hline
\end{tabular}

Já na CI, \#Moreninha apresentou em seu texto uma sequência temporal das etapas de sua vida (Exemplo 8), o que caracteriza o propósito da produção textual que é um relato autobiográfico, pois relata os eventos de sua vida e se estrutura em etapas e fases esperadas para o gênero.

\begin{tabular}{|c|c|c|}
\hline 8 & $\begin{array}{l}\text { Nasci no dia } 24 \text { de maio de } 1995 \text { e já tinha um irmão }[\ldots] \\
\text { Na minha adolescência, com } 12 \text { anos de idade como toda a adolescente }[\ldots] \\
\text { Já na minha juventude aos } 14 \text { anos parei de estudar e }[\ldots] \\
\text { Na vida de adulta já com } 17 \text { anos resolvi }[\ldots]\end{array}$ & \# Moreninha2 \\
\hline
\end{tabular}

No que diz respeito ao critério conjunção, podemos dizer que as relações lógicas estabelecidas na construção dos textos da primeira versão (CE) nem sempre estavam adequadas. Pudemos perceber que os alunos tinham dúvidas quanto ao emprego dessas relações, o que nos motivou a realizar, durante o processo, exercícios específicos para sanar tais dificuldades. O Exemplo 9 mostra o caso de uma aluna que emprega "mas" (conjunção) de modo confuso; o Exemplo 10 não tem sucesso ao tentar estabelecer uma relação de explicação para sua dor.

\begin{tabular}{|l|l|l|}
\hline 9 & Tem gente que vive reclamando da vida dos pais mas eu não amo eles. & \#Boneca1 \\
\hline 10 & $\begin{array}{l}\text { Minha mãe, após perder minha mãe sofri muito, pois eramos um casal de filhos, } \\
\text { nosso pai não possuía profissão definida, }\end{array}$ & \#Falcão1 \\
\hline
\end{tabular}


Com a aplicação de exercícios específicos, na CI podemos considerar, no geral, que as conjunções usadas nas produções textuais estabeleceram relações lógicas adequadas de modo a produzir um todo coerente, ligando palavras, orações e parágrafos ao longo do texto, estabelecendo, principalmente, relações de oposição, adição e explicação, como observamos nos exemplos 11 e 12.

\begin{tabular}{|c|c|c|}
\hline 11 & $\begin{array}{l}\text { Hoje, com } 23 \text { anos, trabalho, estudo, ainda moro com meus pais e tenho uma vida } \\
\text { boa. namoro há quatro anos e pretendo começar a construir minha casa. }\end{array}$ & \# Boneca2 \\
\hline 12 & $\begin{array}{l}\text { Aos } 5 \text { de idade sofri o mais duro golpe da minha vida, perdi a coisa mais preciosa } \\
\text { que alguém pode ter, minha mãe. Após esse fato fiquei totalmente desorientado, } \\
\text { pois uma criança com essa idade o quê pode saber sobre a vida. }\end{array}$ & \#Falcão2 \\
\hline
\end{tabular}

Já em relação à avaliatividade, em que o participante expressa seus sentimentos, juízos e apreciações - em geral por meio de adjetivos, grupos nominais e advérbios de intensidade e de modo -, a maioria fez bom uso dos recursos linguísticos para avaliar, valendo-se principalmente da apreciação e de alguns casos de afeto (exemplos 13 e 14). Alguns alunos, entretanto, exageraram no uso de avaliativos, o que não é uma característica do relato autobiográfico.

\begin{tabular}{|l|l|l|}
\hline 13 & $\begin{array}{l}\text { E me tornei assim um homem apaixonado pela vida, pelas pessoas, animais e } \\
\text { tudo aquilo que vive e ama, mas principalmente um adorador por excelência, } \\
\text { pois apesar de tantos percalços, lutas e adversidades, que encontramos em } \\
\text { nossa vida, ao olharmos para o céu termos a mais cingela de todas as alegrias ao } \\
\text { percebermos que entre as nuvens temos um motivo para sorrir. }\end{array}$ & \#Gabiru1 \\
\hline 14 & $\begin{array}{l}\text { Quando eu era criança tive a melhor infância com meu amigo EA, conheci ele } \\
\text { quando tive } 5 \text { anos, somos amigos até hoje, considero como um irmão para } \\
\text { mim, o pai do meu amigo E que se chama A era muito divertido, ajudava nós a } \\
\text { fazer anarquia e era muito engraçado. A única coisa que me arrependo na minha } \\
\text { infância foi não ter dado muita importância aos estudos, rodei muitas vezes e } \\
\text { vejo que isso prejudicou minha vida. }\end{array}$ & Sonhador 2 \\
\hline
\end{tabular}

No que se refere à identificação, os alunos, em CE, deixaram claro, por meio da coesão, a quem ou ao que estão se referindo em cada oração, como vemos no Exemplo 13 e, no 14, o mesmo ocorrendo em CI. 


\begin{tabular}{|c|l|l|l|}
\hline 13 & $\begin{array}{l}\text { Tudo começou quando minha mãe conheceu meu pai em um baile, ele era } \\
\text { baterista de uma banda, ela mãe de quatro filhos, ele queria festa e farra... }\end{array}$ & \#Negra1 \\
\hline 14 & $\begin{array}{l}\text { Eu, Negra, nasci dia 19 de abril de mil novecentos e sessenta e oito em Tupanciretã, } \\
\text { sou a quinta filha de oito irmãos, filha de MOM e AG, tenho 48 anos, tenho dois filhos } \\
\text { de meu companheiro OM, estamos juntos há } 26 \text { anos. Com poucos meses de vida } \\
\text { meu pai se separou de minha mãe e os outros irmãos que vieram depois de outro } \\
\text { relacionamento de minha mãe, nós os filhos mais velhos tivemos que cuidar para } \\
\text { nossa mãe trabalhar, pois passávamos dificuldades. }\end{array}$ & \# Neg2 \\
\hline
\end{tabular}

$\mathrm{Na}$ última versão, os alunos alcançaram conceito Muito Bom em todos os itens no critério discurso. Atribuímos essa evolução de conceitos nos critérios contexto e discurso ao planejamento que fizemos e executamos em nosso plano de trabalho.

\subsubsection{Gramática}

No tocante ao critério gramática, fizemos o cotejo entre as fases CE e CI no que se refere a componentes gramaticais, ortografia e pontuação. Aqui também foi observada a apresentação física do material produzido pelos alunos.

Nas produções da primeira fase (CE), encontramos muitos erros de grafia, desde troca ou supressão de letras até diminuição de sílabas. Já esperávamos certa dificuldade, mas os textos mostraram-se bastante frágeis quanto à escrita de certas palavras. Atribuímos essa fragilidade ao fato de os alunos dessa turma terem interrompido seus estudos e adiado por muitos anos seu retorno aos bancos escolares.

\begin{tabular}{|l|l|l|}
\hline 15 & $\begin{array}{l}\text { A minha infância foi difícil, com apenas cinco anos de idade perdi a coisa mais } \\
\text { peciosa que eu possuia. }\end{array}$ & \#Falcão1 \\
\hline 16 & $\begin{array}{l}\text { Por meus pais serem aucolatras, não conseguiram ficar juntos e com a separação, } \\
\text { minha mãe passou a beber mais... }\end{array}$ & \#Negra1 \\
\hline 17 & $\begin{array}{l}\text { A minha vó era e é até hoje uma pessoa muito relijiosa mas também bem dificil } \\
\text { de lidar então tive uma infância + ou - boa na medida do posivel fui estudar e ia na } \\
\text { igreja fazer catequeze e tudo mais era a diversão do final de semana ir a missa ou no } \\
\text { campo ver o jogo de futbool. }\end{array}$ & \# \\
\hline
\end{tabular}


Constatamos que, na fase da CI, a maioria dos problemas de grafia foram sanados, embora alguns ainda permanecessem. Os exemplos 18 constitui uma amostra do progresso de um aluno.

\begin{tabular}{|l|l|l|}
\hline 18 & $\begin{array}{l}\text { Aos } 5 \text { de idade sofri o mais duro golpe da minha vida, perdi a coisa mais preciosa que } \\
\text { alguém pode ter, minha mãe. }\end{array}$ & \#Falcão2 \\
\hline
\end{tabular}

$\mathrm{Na}$ análise dos relatos da primeira fase, detectamos também inúmeros problemas de pontuação, o que, muitas vezes, prejudicou a compreensão de algumas produções. Em alguns casos o escritor seguiu o fluxo do pensamento e não pontuou o parágrafo todo, gerando, em vários trechos, dificuldade de leitura (Exemplo 21).

\begin{tabular}{|l|l|l|l|}
\hline 19 & $\begin{array}{l}\text { Meu nome é Caçula, tenho } 21 \text { anos, trabalho em um frigorífico a } 3 \text { anos exercendo o } \\
\text { serviço de Inspeção Federal, moro em Júlio de Castilhos, retornei os estudos com o } \\
\text { objetivo de concluir o ensino médio e aproveitar o técnico integrado junto para um } \\
\text { melhor conhecimento, para que em breve eu consiga alcançar meus objetivos, vencer } \\
\text { obstáculos me formar em medicina veterinária, na qual tenho imenso amor pelos } \\
\text { animais, tenho dois animais de estimação que para mim são como filhos. }\end{array}$ & \#Caçula1 \\
\hline
\end{tabular}

\section{Em 22 podemos observar a evolução no emprego da pontuação.}

\begin{tabular}{|l|l|l|}
\hline 20 & $\begin{array}{l}\text { Meu nome é Caçula, nasci no dia } 24 \text { de agosto de } 1994 \text { em Júlio de Castilhos, tenho } \\
22 \text { anos, sou filha de RR e CT, tenho uma irmã de } 16 \text { anos que se chama L e um irmão } \\
\text { de } 21 \text { anos que se chama W. }\end{array}$ & $\begin{array}{l}\text { A minha infância foi muito feliz junto com meus irmãos e primos, brincávamos de } \\
\text { pega pega, amarelinha, jogávamos bola, andávamos a cavalo. Aos } 7 \text { anos fui para a } \\
\text { escola que era no interior mesmo, tinha apenas uma professora que ensinava todas as } \\
\text { matérias e ainda fazia lanches para nós e limpava toda a escola. }\end{array}$ \\
\hline
\end{tabular}

No critério apresentação, reparamos margens irregulares, falta de espaçamento para o início dos parágrafos, sendo estes mal estruturados com disposição incorreta e grafia pouco legível. Também apareceram rasuras como riscos e uso de líquidos brancos para apagar palavras, o que deixa o texto com aspecto de "sujo". Quanto à apresentação do trabalho, na última versão, os alunos foram mais cuidadosos na utilização dos parágrafos, com a letra e evitando borrões. 


\subsubsection{Avaliação dos resultados}

No Quadro 3, expomos o comparativo das versões dos relatos inicial e final de acordo com os critérios analisados: contexto, discurso e gramática.

QUADRO 3 - Comparativo das versões dos relatos inicial e final de acordo com os critérios: Contexto, discurso e gramática

\begin{tabular}{|c|c|c|c|c|c|c|c|c|c|c|c|c|c|c|c|c|c|c|c|c|c|c|c|c|c|c|c|}
\hline & & & & & I & of & ExTo & & & & & & & & DISC: & URSC & & & & & & & GRA & mant & & & \\
\hline $\begin{array}{l}\hat{A} \\
\hat{U} \\
\mathbf{L} \\
\mathrm{R} \\
\mathrm{R} \\
\mathbf{E}\end{array}$ & 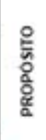 & & $\begin{array}{l}\tilde{a} \\
\frac{a}{\alpha} \\
E\end{array}$ & & 㞾 & & 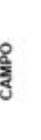 & & & & & & 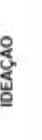 & 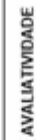 & & & $\frac{8}{2}$ & 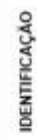 & & & $\frac{\mathbb{Z}}{\frac{\mathbb{Z}}{5}}$ & 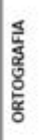 & & 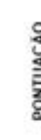 & ta & & \\
\hline Vertio & 12 & 21 & 12 & 1 & 3 & 1 & 3 & 1 & 3 & 1 & 3 & 1 & 3 & 1 & 3 & 1 & 3 & 1 & 3 & 1 & 3 & 1 & 3 & 1 & 3 & 1 & 3 \\
\hline - Gatirv & A $\mathrm{NE}$ & 81 & Me & 1 & Me & 1 & Me & M & Me & R & Me & R & 19 & R & ve & 11 & м⿻ & $m$ & Me & $R$ & Me & R & Me & R & we & B & мต \\
\hline - Laravinasta & \begin{tabular}{|l|l|} 
ME \\
\end{tabular} & \begin{tabular}{l|l}
18 & $R$
\end{tabular} & $\begin{array}{ll}\text { 9 } & \mathrm{Me} \\
\end{array}$ & A & Me & $B$ & Me & 8 & Ne & $R$ & Me & $\theta$ & Ne & A & Me & 8 & MB & Me & Me & $R$ & ME & $R$ & Me & 8 & Me & $B$ & Me \\
\hline - Andoriths & A. ve & 8 & Me & a & Me & $R$ & Mo & me & Me & R & Me & a & Ne & R & ve & A. & Me & mo & Me & B & Me & B & mo & R & Me & B & Me \\
\hline $\begin{array}{l}\text { Caplio } \\
\text { Rostipo }\end{array}$ & \begin{tabular}{|l|l|}
1 & NE \\
\end{tabular} & 81 & \begin{tabular}{|l|l} 
& ME \\
\end{tabular} & 1 & me & 1 & Me & M & Me & $M \theta$ & Me & R & Me & A & Me & 8 & $\Delta$ & ME & Me & 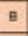 & No & M8 & Me & 8 & Me & Me & ve \\
\hline - Negra & B ME & \begin{tabular}{l|l}
18 & $R$ \\
\end{tabular} & 9 ME & A & Me & B & Me & Me & Me & $B$ & ме & $B$ & 198 & 8 & we & $\begin{array}{ll} \\
\end{array}$ & Me & Me & Me & $B$ & Me & Me & Me & B & we & $B$ & Me \\
\hline - Bonecas & \begin{tabular}{|l|l} 
& Ne \\
\end{tabular} & 181 & \begin{tabular}{|l|l}
1 & Me
\end{tabular} & 1 & Me & R & Me & me & Ne & 8 & me & R & Me & | & บe & 8 & Me & $\mathrm{me}$ & Me & 8 & Mo & Mo & Me & B & Me & 6 & Me \\
\hline - Drica & \begin{tabular}{|l|l|l} 
M & ME \\
\end{tabular} & \begin{tabular}{l|l}
$\theta$ & $R$
\end{tabular} & \begin{tabular}{|l|l}
9 & MB \\
\end{tabular} & A & Me & $R$ & Me & Me & Ne & 8 & Ne & R & Me & 8 & ve & \begin{tabular}{|l|l|}
8 \\
\end{tabular} & 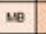 & $M \theta$ & Me & $B$ & Mos & B & Me & $R$ & Me & e & M \\
\hline - Mocenenimas & \begin{tabular}{|l|l|}
1 & Me \\
\end{tabular} & & \begin{tabular}{|l|l} 
& ME
\end{tabular} & 1 & Me & $R$ & Me & me & Ne & $B$ & Ne & $R$ & MB & a & Me & R. & мe & $M$ & Me & 8 & Mo & $B$ & Me & 1 & Me & 8 & ME \\
\hline - casulas & $\begin{array}{ll}1 \\
\end{array}$ & 8.1 & $\begin{array}{ll}1 & \text { Me }\end{array}$ & 1 & Me & 1 & Me & me & ne & 8 & ve & A & 10 & A & ve & is & $\mathbf{s}$ & we & Me & 8 & Me & Me & Mo & B & Me & Ne & 96 \\
\hline OFalcico & \begin{tabular}{|l|l} 
A & ME \\
\end{tabular} & & $\begin{array}{ll}9 & \text { Me } \\
\end{array}$ & A & Me & $R$ & Mo & ne & we & $\theta$ & Me & $R$ & M⿻ & B & ve & 8 & Me & we & Me & $\theta$ & Mes & $B$ & Me & $m e$ & Me & $\theta$ & ME \\
\hline - Anvo & A $\mathrm{NE}$ & 8 . & $\begin{array}{l}\text { 9 } \\
\text { a }\end{array}$ & A & Me & R & Me & Me & Me & 8 & ne & a & Me & A & ve & ค. & $M B$ & $\mathrm{Me}$ & мe & $\theta$ & Me & E & Me & R & me & If & Me \\
\hline 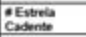 & \begin{tabular}{|l|l|} 
9 & ve \\
\end{tabular} & & 9 & R & me & $R$ & ne & Me & ve & A & ne & R & $\mathrm{Me}$ & - & ve & . & Me & ne & Me & $\theta$ & мe & $R$ & e & $R$ & Me & a & $M 6$ \\
\hline - Lulu & \begin{tabular}{|l|l|l} 
A & VE \\
\end{tabular} & 8 क & $\begin{array}{ll}9 & =0\end{array}$ & A & Me & $R$ & Me & Me & Ne & $R$ & me & $R$ & Me & 1 & ve & R & Me & 10 & Me & $R$ & $B$ & $R$ & Me & R & Me & $R$ & Me \\
\hline - Socontador & A $\mathrm{Ne}$ & 8 & 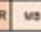 & A & Me & $R$ & $M$ & me & ne & $B$ & 10 & $\pi$ & ME & |R & ve & ค. & $M B$ & 8 & Me & 8 & $\mathrm{Me}$ & B & Me & B & ne & B & MB \\
\hline
\end{tabular}

Fonte: Dados da pesquisa

Cotejando-se a primeira versão com a última, os resultados foram acima do esperado. No final, os estudantes redigiram relatos que atenderam plenamente aos critérios elencados por nós. Acreditamos que contribuiu para isso a elaboração cuidadosa do plano de trabalho e a aplicação sequenciada das atividades, com progressos e retornos. Diante disso, foi possível identificar a competência linguística de uma turma de EJA no que se refere ao trabalho de leitura e produção de textos, bem como a manutenção de uma postura dialógica constante com os alunos em relação a suas preferências, necessidades ou fragilidades. Ainda foi exequível a realização de avaliações diagnósticas em todas as etapas do trabalho, com possibilidade de comparação da competência linguística dos alunos nas produções iniciais com as finais. 


\section{Considerações finais}

Os estudos sobre Pedagogia de Gêneros no Brasil ainda são incipientes, e novas pesquisas precisam ser realizadas. Sugerimos trabalhos sobre outros gêneros textuais em EJA e também em outras modalidades de ensino, principalmente no ensino fundamental, período adequado para a formação de leitores e escritores competentes.

Os textos produzidos inicialmente foram comparados com os últimos e foi gratificante perceber o avanço dos alunos em relação a suas produções. As avaliações iniciais obtiveram conceitos, basicamente, regulares, e após a aplicação do ciclo, predominou o conceito muito bom.

Podemos afirmar que, com o auxílio dos critérios de avaliação elaborados pelos estudiosos australianos identificamos, em todas as etapas do nosso plano de trabalho, a competência linguística da turma pesquisada. Na etapa da Construção Espontânea observamos que as maiores fragilidades estavam nos critérios contexto e gramática. Encontramos também inconsistências no critério discurso. A experiência vivida com os alunos de EJA do IFFar mostrou-nos que, amparados em pressupostos teóricos consistentes, materiais e metodologias adequadas, os alunos demonstram sensível melhoria no processo de escritura.

Pelo que observamos no decorrer da aplicação do plano de trabalho, podemos dizer que o relato autobiográfico se apresenta como um importante instrumento para o professor, pois por meio dele podemos conhecer melhor nosso aluno, entendendo o seu perfil e suas nuances. Além disso, escrever sobre si mesmo proporciona a ele melhor conhecimento de si próprio, o que facilitará, certamente, suas relações com o mundo.

Cada relato descreve uma história pessoal e única, resultante da vida pessoal de cada um. Sem dúvida, existem muitas outras trajetórias além das que foram contadas, mas o importante é que os alunos tiveram a oportunidade de expor parte da sua história de vida, identificando seus desejos, suas capacidades e suas limitações, bem como refletiram sobre o que passaram e discutiram temas como abandono, drogas, violência, falta de recursos e o que fazer para que seus filhos não passem pelos mesmos problemas ou que estejam mais preparados para enfrentá-los.

Além disso, a socialização dos textos foi muito importante, dado que foi possível falar, ser ouvido e ouvir o outro, bem como valorizar a produção e a história do colega. Assim, podemos dizer que a produção dos relatos propiciou uma aprendizagem prazerosa e relevante, pois os alunos foram 
protagonistas dessa história, reconstruindo trajetos de vida marcados por perdas e sonhos que esperam realizar.

Temos consciência de que essa teoria não é isenta de críticas, mas ela tem muito a acrescentar ao ensino, pois sua aplicação impulsiona o amadurecimento linguístico dos alunos e propicia o trabalho com o letramento crítico. Paralelamente às etapas do ciclo, é extremamente importante que o professor promova esse tipo de trabalho com os alunos de modo a suscitar posicionamentos tanto na análise como na produção dos textos.

Tendo em vista a experiência que adquirimos no período de aplicação de nosso plano de trabalho, sugerimos a inserção de uma etapa inicial, a ser aplicada antes das atividades de Desconstrução. Estamos propondo que o ciclo de ensino e aprendizagem inclua, na sua execução, a etapa de Construção Espontânea, utilizada por nós neste estudo. Defendemos que essa etapa inicial é extremamente significativa, pois ajuda o professor a avaliar o conhecimento do aluno sobre o gênero a ser trabalhado. A Figura 5 ilustra nossa proposta.

FIGURA 5 - Nova versão para o ciclo de ensino e aprendizagem da Escola de Sydney
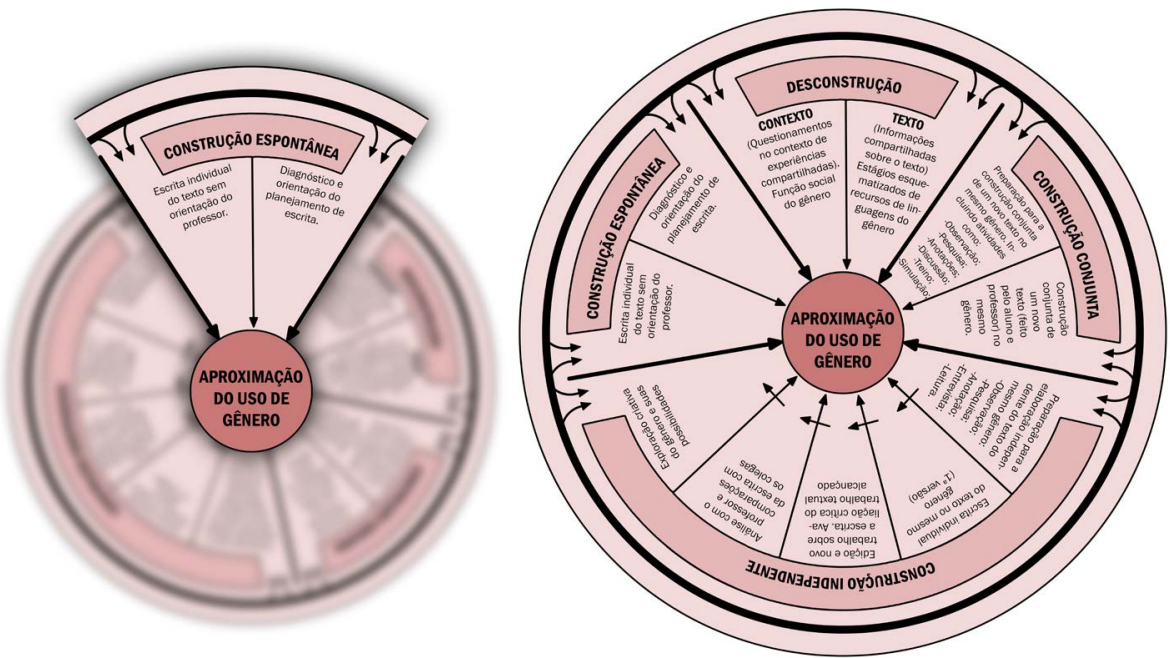

Fonte: adaptado de Rose e Martin (2012, p. 64). ${ }^{11}$

${ }^{11}$ Ilustração adaptada pelo designer André Silva. 
As finalidades e funções específicas da modalidade de ensino EJA

indicam que em todas as idades e em todas as épocas da vida, é possível formar-se, desenvolver-se e constituir conhecimentos, habilidades, competências e valores que transcendam os espaços formais da escolaridade e conduzam à realização de si e ao reconhecimento do outro como sujeito (BRASIL, 2000, p. 12).

Parafraseando Rose e Martin (2012), neste estudo procuramos mostrar que a Pedagogia de Gêneros possibilita ao estudante melhorar suas habilidades de leitura e escrita, aumentando seu desempenho na escola, pelo menos dentro do padrão esperado em seu nível escolar. Com isso, podemos afirmar que todos, mesmo aqueles que apresentam muitas dificuldades, têm condições de produzir bons textos desde que lhes sejam proporcionadas condições viáveis para isso, como uma proposta clara de qual é o gênero a ser produzido.

Para encerrar o ciclo de aprendizagem, compilamos com os alunos uma coletânea dos textos produzidos na última versão e publicamos um livro intitulado Nossa vida, nossa História, o que foi motivo de orgulho para todos. Poder sentir-se autor e autografar um livro consistiu, para nós, dar voz a um grupo que, normalmente, está destinado ao silenciamento.

Uma última observação se faz necessária: refletindo sobre a construção do texto e sobre as sugestões dos alunos, concluímos que o trabalho com gêneros é um recurso poderoso para a discussão dos problemas sociais e políticos que todos vivenciamos. O texto, se visto criticamente, é um repositório de valores, crenças e desejos de quem o produz. Nesse sentido, o trabalho do professor de linguagem(ns) passa a ocupar uma posição de destaque no cenário escola.

\section{Referências}

BAWARSHI, A. S.; REIFF, M. J. Gênero: história, teoria, pesquisa, ensino. Tradução de Benedito Gomes Bezerra. São Paulo: Parábola, 2013. p. 46-59.

BAKHTIN, M. Estética da criação verbal. 4. ed. São Paulo: Martins Fontes, 2003.

BRASIL. Parecer CNE/CEB 11/ 2000. Diretrizes Curriculares Nacionais para a Educação de Jovens e Adultos. Diário Oficial da União, Brasília, DF, Seção 1e, p. 15, 9 jun. 2000. Disponível em: https://bit.ly/2SruH0p. Acesso em: 21 abr. 2016. 
FUZER, C. Ateliê de textos para ler e reinventar estórias: do contexto ao texto e viceversa. Santa Maria: Editora da UFSM, 2017.

FUZER, C. et al. Experiência de desconstrução de gênero e escrita conjunta no projeto Ateliê de Textos. In: SEMINÁRIO INTERNACIONAL DE EDUCAÇÃO, 20., 2015, Cachoeira do Sul. Anais [...]. Cachoeira do Sul: Ulbra, 2015. v. 1, p. 1-12.

FUZER, C. et al. O ciclo de ensino e aprendizagem de gêneros no projeto de extensão Ateliê de Textos. In: SEMINÁRIO DE EXTENSÃO UNIVERSITÁRIA DA REGIÃO SUL, 34., 2016, Camboriú. Anais [...]. Camboriú: IFC, 2016. p. 700-704.

GOUVEIA, C. A. M. A escola como sistema de géneros: conhecimento, aprendizagem e transversalidade. In: MATEUS, M. H. M.; SOLLA, L. (ed.). Ensino do português como língua não materna: estratégias, materiais e formação. Lisboa: Iltec; Fundação Calouste Gulbenkian, 2013. p. 441-461.

HALLIDAY, M. A. K. Part I. In: HALLIDAY, M. A. K.; HASAN, R. Language, Context and Text: Aspects of a Language in a Social-Semiotic Perspective. Oxford: Oxford University Press, 1985. p. 3-43.

HALLIDAY, M. A. K. An Introduction to Functional Grammar. 2. ed. London: Edward Arnold, 1994.

HALLIDAY, M. A. K.; MATTHIESSEN, C. M. I. M. Halliday's Introduction to Functional Grammar. 4. ed. London: Routledge, 2014. Doi: https://doi. org/10.4324/9780203783771

HASAN, R. Part II. In: HALLIDAY, M. A. K.; HASAN, R. Language, Context and Text. Aspects of Language in a Social-Semiotic Perspective. Oxford: Oxford University Press, 1989.

MARTIN, J. R.; ROSE, D. Working with Discourse. New York: Continuum, 2007. p. 8-9.

MARTIN, J. R.; ROSE, D. Genre Relations: Mapping Culture. London: Equinox, 2008. p. $97-136$.

MENDES, M. O. H. Abordagem de base genológica no ensino do português como língua não materna. 2014. Tese (Mestrado em Língua e Cultura Portuguesa) - Faculdade de Letras, Universidade de Lisboa, Lisboa, 2014.

MUNIZ DA SILVA, E. C. Gêneros e práticas de letramento no ensino fundamental. 2007. Tese (Doutorado em Linguística) - Universidade de Brasília, Brasília, DF, 2007. 
MUNIZ DA SILVA, E. C. Ciclo de aprendizagem baseado em gênero. Linguagem: Estudos e Pesquisas, Catalão, v. 19, n. 2, p. 19-37, jul.-dez. 2015.

OLIVEIRA, S. M. N.; CABRAL, S. R. S. Relatos autobiográficos à luz da pedagogia de gêneros: uma intervenção em classes de PROEJA. In: SEMINÁRIO INTERNACIONAL DE EDUCAÇÃO, XXI., 2016, Cachoeira do Sul. Resumos expandidos [...]. Cachoeira do Sul: ULBRA, 2016. n. 1, p. 1-6, 2016.

ROSE, D. Reading genre: a new wave of analysis. Linguistics and the Human Sciences, Sheffield, v. 2 n. 2, p. 185-204, 2006. Disponível em: https://bit.ly/2Ejouyn. Acesso em: 10 jan. 2017.

ROSE, D. Writing as Linguistic Mastery: the Development of Genre Based Literacy Pedagogy. In: MYHILL, D. et al. (ed.). Handbook of Writing Development. London: Sage, 2008.

ROSE, D. Genre in Sydney School. In: GEE, J. P.; HANDFORD, M. (ed.). The Routledge Handbook of Discourse Analysis. London: Routledge, 2010. Doi: https:// doi.org/10.4324/9780203809068.ch15

ROSE, D. Genre, Knowledge and Pedagogy in the "Sydney School". ARTEMEVA, N.; FREEDMAN, A. (ed.). Trends and Traditions in Genre Studies. Alberta: Inkshed, 2015a. Disponível em: https://bit.ly/2SryMSd. Acesso em: 10 jan. 2017.

ROSE, D. Accelerating Learning and Closing the Gap. Sydney: Reading to Learn, 2015b. CD Course Book 2.

ROSE, D.; MARTIN, J. R. Learning to Write, Reading to Learn: Genre, Knowledge and Pedagogy in the Sydney School. London: Equinox, 2012.

ROTHERY, J. Making Changes: Developing an Educational Linguistics. In: HASAN, R.; WILLIAMS, G. (org.). Literacy in Society. London: Longman, 1996. p. 86-123.

SILVA, W. R. Gêneros em práticas escolares de linguagens: currículo e formação do professor. Revista Brasileira de Linguistica Aplicada, Belo Horizonte, v. 15, n. 4, p. 1023-1055, 2015. Doi: https://doi.org/10.1590/1984-639820156170

Data de submissão: 17/10/2018. Data de aprovação: 11/2/2019. 